\title{
Marx e a literatura em $O$ capital
}

SANDRA SOARES DELLA FONTE I

$\mathrm{E}$ M GERAL, a história do pensamento ocidental é marcada por vários eventos que ilustram a supremacia do conceitual sobre o expressivo, como a proposta de expulsão do artista da república idealizada por Platão (1997) e a própria constituição da Estética no século XVIII como campo filosófico particular e inferior (Baumgarten, 1993). A partir da modernidade, essa supremacia ganha sua formulação máxima na sujeição da imaginação ao ideal da ciência objetiva, defendida pelo mais eminente representante do positivismo do século XIX: “[...] a subordinação constante da imaginação à observação foi unanimemente reconhecida como a primeira condição fundamental de toda especulação científica sadia" (Comte, 1978, p.49).

Essa história ganha determinadas nuances quando adentra relações de campos específicos. Ao compor o estudo e a avaliação de uma obra literária ficcional particular ou ao eleger como objeto de estudo a natureza e os atributos gerais da arte das palavras, os discursos filosófico e científico se arrogam uma posição de superioridade; seu apanágio em relação à arte literária fala dessa sujeição do expressivo ao trabalho do pensamento.

Desviar-se desse modus operandi tem sido um desafio; afinal, requer folhear o revés de uma tradição em busca de inspiração para a construção de novos modos de diálogo não hierarquizados entre essas dimensões do existir e do conhecer humano.

Dentro desse esforço, a opção neste artigo é explorar a obra de Karl Marx, autor cuja importância teórica e prática para a contemporaneidade é reconhecida. Diante das preocupações apresentadas, contudo, essa escolha pode soar um tanto incomum. Alguns filtros de leitura da obra marxiana têm colaborado para rarefazer pesquisas nesse horizonte. Chamam a atenção duas orientações elaboradas por gerações marxistas. Uma delas caracteriza a constituição da obra marxiana por um encontro tripartite entre filosofia alemã (Hegel e Feuerbach), Economia Política e socialismo utópico. Essas seriam as fontes ou partes constitutivas do marxismo (Kautsky, s. d.; Lenin, 1986). A outra orientação distingue um período na obra marxiana de uma problemática ideológica, na qual Marx seria um pré-marxista de uma outra fase de ruptura epistemológica, a partir da qual suas reflexões se tornam científicas e, de fato, ele se apresentaria como o Marx propriamente dito (Althusser, 1979).

Muitas restrições podem ser endereçadas a essas duas orientações. Interes- 
sa, no momento, observar os limites que ambas impõem para se acolher ou se discutir a formação literária de Marx e a presença desse aspecto formativo em sua obra, seja porque a literatura ficcional não se caracteriza como um tema específico privilegiado por Marx, seja porque ela se torna periférica ou sem sentido quando o estatuto de cientificidade se torna critério de avaliação da maturidade ou potencialidade de suas reflexões.

Entretanto, relatos indicam que, em sua vida cotidiana e familiar, Marx tinha apreço pelas manifestações artísticas, em especial pela literatura; tal hábito foi cultivado desde tenra idade e se estendeu aos seus estudos universitários (Marx, 2011; Lafargue, 1974). Ademais, os juízos estéticos de Marx não se circunscreveram ao âmbito dos seus gostos pessoais; eles chegaram a penetrar seus trabalhos e a nutrir, em parte, suas reflexões sobre a estética e também suas argumentações filosóficas e científicas em geral.

A questão da arte nos textos marxianos pode ser abordada, pelo menos, por duas vias. Na primeira - a perspectiva mais explorada pela produção acadêmica existente -, evidenciam-se suas reflexões (muitas vezes, em parceria com Friedrich Engels) sobre os problemas estéticos e, de modo específico, os artísticos (Lifschitz, 1976; Vázquez, 1978; Gunnarson, [19_] _ Lukács, 2012; Sodré, 1968; Cotrim, 2012; 2013; Frederico, 2005). A estética e a arte aparecem como objeto da reflexão e Marx apresenta-se como um teórico e crítico de arte. $\mathrm{Na}$ segunda via, o discurso figurativo e artístico adentra o texto conceitual e se faz presente nele.

Sob o foco da primeira via, ressalta-se que os problemas estéticos não ganharam um lugar especial em seu trabalho a ponto de serem tratados em uma obra sobre o assunto. Pelo contrário, suas ideias estéticas estão pulverizadas em toda sua produção "[...] numa forma certamente concisa e desarticulada" (Vázquez, 1978, p.11) e também de modo irregular. Por mais que a hegemonia de um marxismo cientificista tenha contribuído para que a elaboração marxiana sobre esse tema permanecesse ignorada ou depreciada, alguns autores identificam que, apesar de poucas, as reflexões de Marx sobre problemas estéticos e artísticos envolvem aspectos centrais e não são acidentais no seu corpo filosófico (Lifschitz, 1976, 2012; Vazquez, 1978; Lukács, 1979, 2012; Gunnarson, [19_] ] . Em outros termos, há uma vinculação de suas reflexões estéticas com o conjunto de seu pensamento. Mészaros (2006, p.173-4) chega a afirmar que as considerações estéticas marxianas estão:

[...] tão intimamente ligadas a outros aspectos de seu pensamento que é impossível compreender adequadamente até mesmo sua concepção econômica sem entender suas ligações estéticas. [...] Desnecessário dizer, assim como não é possível apreciar o pensamento econômico de Marx ignorando suas opiniões sobre a arte, é igualmente impossível compreender o significado de seus enunciados sobre as questões estéticas sem levar em conta as suas interligações econômicas. 
$\mathrm{Na}$ segunda via de tratamento da arte na obra marxiana, trata-se de perquirir um movimento diverso no qual o conhecimento artístico adentra o universo conceitual e passa a compô-lo. Em outros termos, examina-se o lugar do elemento expressivo na sua teorização.

De alguma maneira, Marx cultivou certa preocupação com o caráter expressivo de sua prosa conceitual. No posfácio da segunda edição de $O$ capital de 1873, Marx (1985) caracteriza o seu método dialético por dois momentos distintos e complementares: o método de pesquisa e o de exposição. Enquanto o primeiro consiste na investigação dos pormenores de um fenômeno e da conexão íntima desses pormenores, o segundo equivale a descrever o movimento do real, trazer, para o plano da idealidade, "[...] a vida da realidade pesquisada" (Marx, 1985, p.16). De alguma maneira, Marx sinaliza a articulação entre o que é pesquisado e a sua forma de exposição, momento no qual o texto propriamente conceitual emerge.

Essa perspectiva também aparece em carta a Engels de 31 de julho de 1865, quando Marx lhe comunica que ainda falta redigir o que, para ele, seria o quarto livro de $O$ capital: "Mas não posso fazer nada antes de concluir tudo. Whatever shortcoming they may have, o mérito dos meus escritos é que constituem um todo artístico e isso só se pode lograr com o meu método de não publicá-los enquanto não os tenha terminado" (Marx; Engels, 2012, p.88). A leitura rápida pode levar à suspeita de uma identidade entre o texto conceitual e o artístico. Porém, há aqui uma ampliação do sentido artístico a todo texto que não apenas afasta o sentido parcelar e adquire coesão, mas também que tenha, por essa razão, sofrido o polimento em sua estrutura enunciativa antes de ser entregue ao público. Qualificar seus textos de um “todo artístico” é um reconhecimento da dimensão estética de sua teorização. Marx atribui a seus escritos conceituais uma dimensão expressiva.

Essa indicação pode, com as devidas mediações, aproximar-se de um conjunto de esforços teóricos contemporâneos (Adorno, 2009; Benjamin, 1984; Duarte, 2008; Gagnebin, 2004) que têm insistido que a forma de apresentação ou exposição é uma questão relevante para o trabalho do pensamento, pois o estilo narrativo não é externo à prosa conceitual (seja científica, seja filosófica). A reflexão conceitual precisa de arquitetura narrativa para poder se dizer.

$\mathrm{Na}$ filosofia contemporânea de legado marxista, Theodor W. Adorno $(2009$, p.21) observa que "[...] para a filosofia a sua apresentação não é algo indiferente e extrínseco, mas imanente à sua ideia. Seu momento expressivo integral, mimético-aconceitual, só é objetivado por meio da apresentação - da linguagem". Portanto, pressupõe-se a "[...] a não-exterioridade entre o conteúdo do filosofema e a sua forma de apresentação [Darstellungsform] convergentes na própria expressão" (Duarte, 1997, p.178).

No caso específico de Marx, o trabalho do conceito se faz como exposição do objeto. Nas palavras de Chagas (2011), o método dialético em Marx articula 
investigação e exposição crítica do objeto. No entanto, em que consiste essa criticidade que articula o conteúdo conceitual e sua forma de exposição?

Ao pinçar algumas reflexões de Adorno (2009), é possível entrever certos aspectos dessa articulação pautados em uma racionalidade ampliada. Sua radicalidade crítica se dá a partir da dialética que, longe do afoite de sínteses apressadas, esgarça o seu momento de negatividade. Por isso, essa dialética negativa se move como antissistema e tem como primado a contradição. Enquanto “[...] uma forma de representação de uma totalidade para a qual nada permanece exterior [...]" (Adorno, 2009, p.29), o sistema se edifica a partir da autarquia do conceito e da pretensão de fazer coincidir imediatamente a ordem das coisas com a das ideias. Como coisificação da consciência humana, ele é índice, no âmbito do conhecimento, da imposição da objetividade social capitalista. A troca tudo iguala; nela impera a violência contra a experiência e as suas determinações particulares. Por isso, sua razão se funda na identidade: "Enquanto princípio de troca, a ratio burguesa realmente assimilou aos sistemas com um sucesso crescente, ainda que potencialmente assassino, tudo aquilo que queria tornar comensurável a si mesma, identificar consigo, deixando sempre cada vez menos de fora" (Adorno, 2009, p.28).

Adorno (2009) aponta para a renovação da teoria que, sem abrir mão dos momentos de verdade do conceito, furta-se a seu desejo de ser absoluto. Se pensar não é uma faculdade meramente formal, o conceito visa a algo além de si; logo, para Adorno (2009), lhe é constitutivo não se satisfazer com sua própria conceptualidade. Não há identidade linear entre conceito e coisa. Portanto, assegurar-se do não conceitual no conceito é condição para que o conceito não seja, segundo Adorno (2009), nulo e se mantenha como conceito de algo. Nas suas palavras, “Ante a intelecção do caráter constitutivo do não-conceitual no conceito dissolve-se a compulsão à identidade que, sem se deter em tal reflexão, o conceito traz consigo" (Adorno, 2009, p.19). Quando reconhece isso, a filosofia (e, poder-se-ia pensar no trabalho teórico de modo geral) “[...] arranca a venda de seus olhos" (ibidem).

O reconhecimento disso por parte de uma teorização renovada a partir da lógica dialética faz a atividade conceitual incorporar como sua atitude aquilo que ela esquece:

O conceito não consegue defender de outro modo a causa daquilo que reprime, a da mimesis, senão na medida em que se apropria de algo dessa mimesis em seu próprio modo de comportamento, sem se perder nela. Dessa forma, o momento estético, ainda que por uma razão totalmente diversa do que em Schelling, não é acidental para a filosofia. (Adorno, 2009, p.21)

Para a presente pesquisa, toma-se como pressuposto o caráter irrevogável do elemento expressivo na atividade teórica e, a partir disso, opta-se pela via que privilegia a presença de elementos figurativos no texto marxiano. Essa tendência de pesquisa é embrionária e tem como marco o livro de Ludovico Silva (2012)1 
no qual o estilo literário de Marx é investigado em termos de metáforas, alegorias e ritmo prosódico. No esforço de contribuir com essa frente de estudo, agrega-se a essa análise a figuração artística, com o foco na literatura, tendo em vista que há “[...] alusões impressionantemente eruditas de Marx à literatura mundial" (Eagleton, 1993, p.7) que acompanham sua obra.

Nesse sentido, demarcam-se as seguintes questões problema desta investigação: como se dá a presença de menções literárias ficcionais em sua obra magna $O$ capital e quais papeis cumprem no contexto de sua argumentação? Em que medida essa forma de diálogo contribui para fomentar vínculos não hierárquicos entre o texto conceitual e o literário ficcional?

Tendo em vista esse conjunto de questões, o livro de Prawer (2011) Marx and world literature (publicado em inglês em 1976 e relançado em 2011) é referencial em sua preocupação de construir um mapa evolutivo cronológico do que Marx disse sobre a literatura e do emprego que dela fez. Considerando a proximidade deste artigo com a pesquisa de Prawer, cabe registrar em que medida a presente investigação não será uma versão alongada do capítulo específico sobre O capital escrito por Prawer. Por certo, compartilha-se a preocupação de Prawer com o uso que Marx realizou de obras literárias ficcionais. Porém, afasta-se de suas motivações. Dentre os incômodos desse autor, encontra-se o fato de que as compilações sobre a questão estética em Marx correm o risco de criar confusão ao misturar seus pronunciamentos realizados em momentos distintos de sua vida. Em contraste com essa preocupação, realiza-se um distanciamento evidente da intenção de sublinhar as ideias estético-artísticas de Marx e da natureza diacrônica do estudo de Prawer. Avizinha-se, desse modo, de uma produção acadêmica nacional incipiente referente a dois artigos (Queiroz; Costa, 2012; Silva, 2015) e uma dissertação (Melo, 2014) que delineiam a presença da ficção literária no discurso marxiano a partir de algumas obras específicas, em especial de $O$ capital.

Ademais, o pano de fundo que impulsiona a presente pesquisa reside em um dos aspectos de seu objetivo geral. Se, por um lado, pretende-se sugerir aprofundamentos e/ou novos caminhos de abordagem da obra de Marx de modo a dissipar simplificações e preconceitos; por outro, almeja-se contribuir para a construção de relações tensas e complementares entre a prosa conceitual e a prosa/poética literária. Por mais que haja notas em Prawer que tangenciem essa problemática, o pôr em xeque a supremacia do conceitual sobre o expressivo não é o seu norte.

Em um olhar apressado, as menções marxianas a obras literárias ficcionais em $O$ capital podem assumir apenas o caráter de epigrafar, finalizar ou ilustrar o seu argumento. Porém, suspeita-se que, afora esse uso ornamental, a apropriação de menções literárias ficcionais não aparece apenas instrumentalizada na prosa conceitual marxiana; ela também possui papel relevante na configuração de seu pensamento. Isto é, em vários momentos, a figura artístico-literária serve de corpo visível de sua reflexão. 
Assim, há, no texto marxiano, um movimento duplo entre a prosa conceitual e o discurso figurativo-artístico que se expressa nas menções literárias ficcionais. Por um lado, o texto conceitual recorre a essas menções para sujeitá-las à função explicativa ou, nos termos adornianos, à comunicação. Sendo $O$ capital um texto conceitual par excelence, sua linguagem visa à transparência e à precisão. Essa natureza de sua prosa tende, então, a tragar as menções literárias ficcionais a partir desse objetivo maior. Entretanto, ao mesmo tempo que faz isso, a prosa conceitual vê-se diante de seu limite ao tentar dizer, de modo transparente, o mundo. Assim, há momentos em que seu suporte reflexivo reside no imaginário figurativo.

Aceita-se, desse modo, a indicação de Silva (2012): a ossatura conceitual marxiana possui uma musculatura expressiva. Não se trata, segundo ele, de uma organização extrínseca dos conceitos e estruturas do conteúdo dado, mas aquilo que engendra a reflexão propriamente dita; não é meio de exposição, mas a própria genética graças à qual o trabalho do pensamento se produz como tal.

Situam-se as menções literárias em $O$ capital também dentro do campo da linguagem figurativa destacado por Ludovico Silva. Ao recorrer ao figurativo-literário, Marx sinaliza que a transparência radical da prosa conceitual ou a sua pretensão não é absoluta. Algumas menções literárias abrem facetas do mundo, geralmente opacas; tornam sensíveis conteúdos objetivos do mundo. Nesse momento, a clareza do texto conceitual recua diante da imaginação literária. Nesse recuo, revela-se a sua fragilidade, mas também sua chance de redenção. Como afirma Adorno (2009), a liberdade do pensamento reside naquilo que ele resiste e repele: o impulso expressivo. Sua liberdade consiste em ser capaz de experimentar-se determinado e, portanto, não livre.

Tal parece ser o caso da inserção de excerto de $A$ divina comédia, de Dante, no final do prefácio à $1^{a}$ edição de $O$ capital. Marx (1985) registra que acolherá críticas científicas com satisfação, mas em relação aos "preconceitos da chamada opinião pública", seguirá a máxima do grande Florentino: "Segui il tuo corso, e lascia dir le genti!" [Segue teu rumo e não te importes com o que os outros digam!] (Marx, 1985, p.7). À primeira vista, a menção aparece como um floreio que finaliza o texto. Porém, chama atenção que o conselho a ser dado ao cientista é retirado da literatura ficcional. Algo semelhante ocorre quando Marx recorre também à citação de Dante no final do prefácio de Para a crítica da economia política: "Mas na entrada para a Ciência - como na entrada do Inferno - é preciso impor a exigência: Qui si convien lasciare ogni sospetto/Ogni viltà convien che sai morta" [Que aqui se afaste toda a suspeita/ Que neste lugar se despreze todo o medo] (Marx, 1987a, p.32). Em ambos os casos, a obra de arte literária mostra-se conselheira do cientista.

Por vezes, as citações literárias compõem o estilo narrativo irônico. O exemplo é novamente do prefácio da $\mathrm{I}^{\mathrm{a}}$ edição de $O$ capital. Nessa obra, Marx tem como objeto de pesquisa "[...] o modo de produção capitalista e as corres- 
pondentes relações de produção e de circulação" (Marx, 1985, p.5); por essa razão, tomou Inglaterra como principal ilustração. No entanto, como a primeira publicação do livro foi em sua língua materna, Marx observa que o leitor alemão pode ficar indiferente ou tranquilizar-se com a ideia de que, na Alemanha, as coisas não são tão ruins. Contra isso, $\operatorname{Marx}(1985$, p.5) o adverte: "De te fabula narratur!" [A história é a teu respeito]. Marx não coloca referência, mas se trata de trecho de Horário em Sátiras (I, 1, 69-70) é: "De que ris? Mudado o nome, a narrativa fala de ti". Ao tentar sensibilizar o leitor alemão, Marx insiste que a situação social na Alemanha é muito pior que a da Inglaterra. Mesmo sendo precária, a estatística social na Alemanha "[...] chega para descerrar o véu, o suficiente para que se pressinta, atrás dele, um rosto de Medusa" (Marx, 1985, p.5). Os alemães ficariam petrificados diante da constituição de comissões de inquérito para apurar, por exemplo, a exploração do trabalho de mulheres e de crianças. Seguindo a mitologia, Marx sabe que a ameaça de Medusa só pode ser contida por Perseu, seu decapitador. Então, para mostrar a gravidade da situação, ele lembra que Perseu tinha capacete para se tornar invisível e perseguir monstros: "Nós, de nossa parte, nos embuçamos com nosso capuz mágico, tapando nossos olhos e nossos ouvidos, para poder negar as monstruosidades existentes" (Marx, 1985, p.5-6). Como se percebe, o estilo irônico de Marx não apenas chama atenção para uma situação nefasta, mas também "[...] pode ser considerada como uma importante ferramenta de crítica social" (Venâncio, 2009 , p.11).

Além de alimento para as ironias textuais, as alusões literárias compõem alegorias e metáforas. Afirma Marx (1985, p.95): cada mercadoria vê na outra o manifestar do seu próprio valor: "Igualitária e cínica de nascença, está sempre pronta a trocar corpo e alma com qualquer outra mercadoria, mesmo que esta seja mais repulsiva do que Maritornes". Em suas relações de troca, as qualidades dos objetos não contam, mesmo sendo a mais repulsiva, promíscua tal como a empregada, também uma espécie de prostituta, que trabalha na primeira hospedaria em que Don Quixote se hospeda, pensando ser um castelo.

Em outro momento, Marx (1985, p.92) pontua: o economista, como "o intérprete da alma da mercadoria", não percebe que o valor-de-troca de pérolas ou diamantes não se deve à propriedade física desses objetos, mas se constitui num atributo social. Os economistas agem tal como uma personagem da peça de Shakespeare Muito barulho por nada: “[...] Dogberry, ensinando ao vigilante noturno Seacoal: 'Ser dotado de um belo físico é uma dádiva das circunstâncias, mas ler e escrever é um dom da natureza" (ibidem, p.93). Nessa referência, Marx usa Dogberry como a figura que personifica a lógica dos economistas políticos; ele toma o ler e o escrever como naturais, assim como os economistas tomam os diamantes e pérolas como um valor inerente e natural.

O recurso à prosopopeia não é pertinente apenas para explicar o fetichismo da mercadoria; torna-se também crucial para abordar o capital. Nesse processo, 
a literatura ficcional tem lugar de destaque quando Marx o associa a algumas figurações, como vampiro, monstro, diabo. Ele afirma: "O capital é trabalho morto que, como um vampiro, se reanima sugando o trabalho vivo e quanto mais o suga, mais forte se torna" (ibidem, p.263). Por isso, "Se o dinheiro, segundo Augier, 'vem ao mundo com uma mancha natural de sangue numa de suas faces', o capital, ao surgir, escorrem-lhe sangue e sujeira, por todos os poros da cabeça aos pés" (ibidem, p.878-9). A distensão da jornada de trabalho para limites extremos responde à demanda de exploração sem fim do capital: "O prolongamento do trabalho além dos limites diurnos naturais, pela noite adentro, serve apenas de paliativo para apaziguar a sede vampiresca do capital pelo sangue vivificante do trabalho" (ibidem, p.290). ${ }^{3}$

$\mathrm{O}$ capitalista incorpora força de trabalho viva à materialidade morta dos elementos que ele comprou; ao fazer isso, "[...] transforma valor, trabalho pretérito, materializado, morto, em capital, em valor que se amplia, um monstro animado que começa a 'trabalhar', como se tivesse o diabo no corpo" (ibidem, p.219-20). Além da imagem sensível do capital como monstro, a expressão "como se tivesse diabo no corpo" vem de uma modificação de verso de Fausto de Goethe, como salienta Prawer. No romance goetheano, a expressão original é "como se tivesse amor no corpo". O contexto é o de um rato envenenado que se debate, corre, sobe e desce até morrer. Essa cena antecipa a entrada de Mefistófeles. O caráter diabólico do capital deriva, em larga medida, de discursos de Mefistófeles ou possui alguma conexão direta com ele (Prawer, 2011).

Cotejar o capital a um vampiro, monstro ou diabo é recurso expressivo que possibilita dar a esse fenômeno uma imagem concreta, o rosto de um ser animado, incontrolável, cujo valor se expande desmesuradamente: "A escolha da metáfora é, assim, importante filosófica e politicamente: através dela, Marx pretende expor um aspecto substantivo do mundo social" (Neocleous, 2003, p.674).

Além disso, permite que alguns estudiosos olhem para a obra magna de Marx como uma espécie particular de "romance de formação" do capital, sob inspiração da literatura gótica de horror do século XIX (Wheen, 2007) ou de romances da era inglesa vitoriana (Kornbluh, 2010; Wheen, 2007).

Aqui também o universo artístico adentra a estrutura narrativa marxiana de modo que sua análise dos fenômenos sociais gera não apenas uma metáfora para o capital, mas assume a composição peculiar de um drama alegórico que revela como o valor, forma social particular existente inclusive em sociedades comerciantes antigas, desenvolve-se como valor gerando valor e se torna estruturante da vida social, sua ossatura, matriz que rege a totalidade e a capilaridade da vida no capitalismo, sujeito da história que vive como parasita com poderes monstruosos: "O capital é a história do Capital tornando-se sujeito, da implacável autoconstituição, da "valorização do valor" que impulsiona este modo de produção. $\mathrm{O}$ artifício do tropo da personificação chama a atenção para o artifício 
e a instabilidade deste sujeito, para as fissuras e crises em seu curso de tornar-se, em sua aventura de Bildung" (Kornbluh, 2010, p.24).

Segundo Mehring (1974, p.247), a alegoria não é, para Marx, um enfeite ou um meio para facilitar a compreensão: “A alegoria, tal como Marx a emprega, é a mão física dos pensamentos, que recebe dela o seu fôlego vital".

Em um nível um tanto paradoxal, a obra de arte literária parece oferecer a Marx figurações que migram do campo artístico e ganham um conteúdo filosófico. O neologismo robinsonada que a crítica literária deriva da personagem Robinson Crusoé e foi inicialmente atribuído às imitações desse gênero literário ganha novos contornos ao chegar ao texto marxiano com tom bastante irônico. Em Introdução de Para a crítica da economia política, ao declarar: "O caçador e o pescador, individuais e isolados, de que partem Smith e Ricardo, pertencem às pobres ficções das robinsonadas do século XVIII" (Marx, 1987a, p.3). Isso se repete em $O$ capital: “A economia política adora imaginar experimentos robinsonianos" (Marx, 1985, p.85).

Para Marx, as ficções de robinsonadas têm correlatos no campo filosófico. O romance não é somente uma alegoria do individualismo moderno. O sentido é que o ser humano abstrato, desprendido de suas relações sociais, ilustra não apenas o coração da sociedade civil, esfera regida pelos interesses particulares, mas é transformado em modelo da gênese da humanidade, um ponto de partida natural da história e não o seu resultado. Ao tomar emprestada a expressão robinsonadas, Marx extrai do âmbito estético-literário uma figuração que é explorada com algum grau de liberdade e ampliada de modo a ganhar um conteúdo filosófico: a naturalização da história.

Diante dos exemplos citados, seguimos a orientação de Silva segundo a qual o conteúdo teórico das reflexões de Marx pode ser percebido na arquitetura textual e essa tarefa é assumida intencionalmente por Marx. Sua crítica conceitual se articula com a "[...] luta contra toda parcimônia ou pobreza linguística" (Silva, 2012, p.17) e, assim, desafia a linguagem científica em sua formalidade e obscurantismo. Nas palavras de Wheen (2007, p.11),

Na época em que escreveu $O$ capital, Marx superava a prosa de convenção com sua radical colagem literária - justapondo vozes e citações de mitologia e literatura, relatório de inspetores de fábrica e contos de fada, nos moldes dos Cantos, de Ezra Pound, ou de A terra desolada, de Eliot. O Capital é tão dissonante quanto Schoenberg, tão angustiante quanto Kafka.

Por isso, “[...] o tecido teórico [de Marx] foi urdido com fios literários concretos. O sistema científico está sustentado por um sistema expressivo" (Silva, 2012, p.11). De alguma maneira, as menções a obras, personagens e autores da literatura ficcional contribuem nesse processo. Portanto, em sua obra magna, há atravessamentos entre a denotação e a conotação, como indica Kornbluh (2010, p.21): “[...] algumas das sugestões mais prementes do texto encontram sua formulação mais potente de modo performativo. O capital diz o que quer 
dizer não apenas por meio de referência denotativa, mas através de formas conotativas, associativas e artísticas que a linguagem faz operar".

Essas cesuras e costuras entre o conotativo e o denotativo, o conceitual e o não conceitual permitem compreender o texto marxiano como uma experimentação guiada pelo esforço de aproximar-se da dinâmica capitalista, orientada pela contradição, que põe sob suspeita qualquer absolutização conceitual. Seu tecido textual traz índices de uma nova racionalidade que, de modo peculiar, assume o impulso mimético ao trabalho do pensamento.

Ainda dentro do corpo hipotético deste artigo, considera-se que essas formas de "invasão" literária no texto conceitual podem significar uma possibilidade, entre outras, de fortalecer a proposição de uma relação não hierárquica entre a linguagem conceitual e a expressiva, na qual o conhecimento conceitual pode adensar sua autoridade e rigor no diálogo com a literatura. Como afirma Adorno (2009, p.24),

[...] expressão e acuro lógico não são possibilidades dicotômicas. Eles necessitam um do outro, nenhum dos dois é sem o outro. A expressão é liberada de sua contingência por meio do pensamento, pelo qual a expressão se empenha exatamente como o pensamento se empenha por ela. O pensamento só se torna conclusivo enquanto algo expresso, somente por meio da apresentação linguística; o que é dito de modo frouxo é mal pensado. Por intermédio da expressão, o acuro lógico é conquistado laboriosamente para o que é expresso.

$\mathrm{O}$ rigor não decorre da hipostasia do conceitual, mas do reconhecimento de suas potencialidades e de seus limites. Por isso, nessa forma renovada de fazer teoria, a expressividade como o não conceitual é seu aspecto incontornável. Marx absorve em seus escritos essa contradição. De modo mais preciso, a composição textual marxiana representa uma experimentação da lógica dialética; ela testemunha a lembrança do que Adorno (2009) chama de verdade e não verdade do exercício conceitual e, portanto, de sua relação tensa e complementar com o expressivo.

Sugere-se que esse posicionamento vai além de um avanço teórico. Mais precisamente, esse avanço tem, em Marx, uma base política. Vincula-se à luta contra a estreiteza e a unilateralidade do desenvolvimento humano decorrente da divisão social do trabalho no capitalismo que fratura e hierarquiza capacidades e faculdades humanas. Carrega em si a utopia de um saber renovado que não se submete à força da identidade do princípio do valor.

\section{Notas}

1 Publicado em língua espanhola em 1971. Utiliza-se a sua tradução para o português.

2 Ainda sem tradução para o português.

3 "Sabemos que Marx gostava de ler histórias de horror, e sabemos que o vampiro era uma forma literária popular no século XIX. Enquanto o romance mais conhecido do 
gênero, Dracula de Bram Stoker, só foi publicado em 1897, após a morte de Marx, o vampiro em geral tinha tido muita cobertura antes disso. Varney, o vampiro de James Malcolm Rymer, por exemplo, foi serializado um ano antes da publicação do Manifesto do Partido Comunista, e estendido a 220 capítulos em 868 páginas” (Neocleous, 2003, p.673).

\section{Referências}

ADORNO, T. W. Dialética negativa. Rio de Janeiro: Zahar, 2009.

ALTHUSSER, L. A favor de Marx. 2.ed. Rio de Janeiro: Zahar, 1979.

BAUMgARTEN, A. G. Estética: a lógica da arte e do poema. Petrópolis: Vozes, 1993. BENJAMIN, W. Origem do drama barroco alemão. Brasília: Brasiliense, 1984.

CHAGAS, E. F. O método dialético de Marx: investigação e exposição crítica do objeto. Sintese - Revista de Filosofia, Belo Horizonte, v.38, n.120, p.55-70, 2011.

COMTE, A. Discurso sobre o espírito positivo. São Paulo: Abril Cultural, 1978. p.41-94.

COTRIM, A. A. Marx e a épica. Communicare, São Paulo, v.12, n.2, p.13-30, 2012.

Tragédia e revolução: uma leitura do debate sobre Franz von Sickingen entre

Marx, Engels e Lassalle. Marx e o marxismo 2013: Marx hoje, 130 anos depois, Niterói:

UFF/ Núcleo Interdisciplinar de Estudos e Pesquisas sobre Marx e o Marxismo, 2013.

DUARTE, R. Adornos: nove ensaios sobre o filósofo frankfurtiano. Belo Horizonte: UFMG, 1997. gos, 2008.

Dizer o que não se deixa dizer: para uma filosofia da expressão. Chapecó: Ar-

EAGLETON, T. A ideologia da estética. Rio de Janeiro: Jorge Zahar Editor, 1993.

FREDERICO, C. A arte em Marx. Revista Novos Rumos, São Paulo, v.19, n.42, ano 20, p.3-24, 2005.

GAGNEBIN, J.-M. As formas literárias da filosofia. In: SOUZA, R. T.; DUARTE, R. (Org.) Filosofia e literatura. Porto Alegre: EDPUCRS, 2004. p.11-20.

Do conceito de Darstellung em Walter Benjamin ou verdade e beleza. Kriterion, Belo Horizonte, v.46, n.112, p.183-90, 2005.

GUNNARSON, G. Estética marxista. Brasília: Alva, [19_].

HORÁCIO. Sátiras. Rio de Janeiro: Ediouro, 1993.

KAUTSKY, K. As três fontes do marxismo. São Paulo: Global, s. d.

KORNBLUH, A. On Marx's Victorian novel. Meditations, v.25, n.1, p.15-25, 2010.

LAFARGUE, P. Os gostos literários de Marx. In: MARX, K.; ENGELS, F. Sobre literatura e arte. Lisboa: Estampa, 1974. p.237-42.

LENIN, V. I. As três fontes e as três partes constitutivas do marxismo. In: Obras escolhidas. t.1. São Paulo: Alfa-Ômega, 1986.

LIFSCHITZ, M. The philosophy of art of Karl Marx. 2.ed. London: Pluto Press Limited, 1976. 
LIFSCHITZ, Mikhail. Prólogo. In: MARX, K.; ENGELS, F. Cultura, arte e literatura. 2. ed. São Paulo: Expressão Popular, 2012. p. 39- 62.

LUKÁCS, G. Introdução a uma estética marxista. Rio de Janeiro: Civilização Brasileira, 1979 .

Introdução aos estudos estéticos de Marx. In: MARX, K.; ENGELS, F. Cultura, arte e literatura. 2.ed. São Paulo: Expressão Popular, 2012. p.11-38.

MARX, E. Karl Marx por Eleanor Marx. Mouro - Revista Marxista, Ideo/Graphos, ano 3, n.4, p.11-18, jan. 2011.

MARX, K. O capital. 10.ed. São Paulo: Difel, 1985. Livro 1. v.I, II.

- Para crítica da Economia Política. 4.ed. São Paulo: Nova Cultural, 1987a.

. O capital. 5.ed. São Paulo: Difel, 1987b. Livro 2. v.III.

. O capital. 6.ed. São Paulo: Difel, 1991. Livro 3. v.IV.

MARX, K.; ENGELS, F. Cultura, arte e literatura. 2.ed. São Paulo: Expressão Popular, 2012.

MEHRING, F. Marx e a alegoria. In: MARX, K.; ENGELS, F. Sobre literatura e arte. Lisboa: Estampa, 1974. p.245-7.

MELO, L. Elementos literários na arquitetura narrativa de Marx. Brasília, 2014. 117f. Dissertação (Mestrado em Sociologia) - Programa de Pós-Graduação em Sociologia, Universidade de Brasília. Brasília, 2014.

MÉSZÁROS, I. A teoria da alienação em Marx. São Paulo: Boitempo, 2006.

NEOCLEOUS, M. The political economy of the dead: Marx's vampires. History of Political Thought, v.XXIV, n.4, p.668-84, 2003.

PLATÃO. A república. São Paulo: Nova Cultural, 1997.

PRAWER, S. S. Karl Marx and world literature. London; New York: Verso, 2011.

QUEIROZ, F. J.; COSTA, F. Marx e a literatura: um estudo à luz do Capital. Revista Eletrônica Arma da Crítica, Fortaleza, n.4, p.11-30, dez. 2012.

SILVA, F. de A. Marx e a literatura. Anais do VIII Colóquio Marx \& Engels (Cemarx), Campinas/Unicamp, 2015. 9p. Disponível em: <https://www.ifch.unicamp.br/formulario_cemarx/selecao/2015/trabalhos2015/Francisco\%20de\%20Assis $\% 20$ Silva $\% 20$ 10594.pdf>. Acesso em: 10 out. 2016.

SILVA, L. O estilo literário de Marx. São Paulo: Expressão Popular, 2012.

SODRÉ, N. W. (Org.) Fundamentos da estética marxista. Rio de Janeiro: Civilização Brasileira, 1968.

SOUZA JÚNIOR, J. Mercadoria, fetichismo e discurso figurado n'O capital. Anais do IV Colóquio Marx \& Engels (Cemarx). Campinas/Unicamp, 2005. 11p. Disponível em: <http://www.unicamp.br/cemarx/ANAIS\%20IV\%20COLOQUIO/ comunica\%E7\%F5es/GTl/gtlm2c3.pdf>. Acesso em: 10 out. 2016.

VÁZQUEZ, A. S. As ideias estéticas de Marx. 2.ed. Rio de Janeiro: Paz e Terra, 1978.

VENÂNCIO, R. O. Ironia e o jornalismo de Karl Marx e Friedrich Engels. Rhêtorikê, n.2, p.1-15, abr. 2009.

WHEEN, F. O Capital de Marx: uma biografia. Rio de Janeiro: Jorge Zahar, 2007. 
RESUMO - A partir da reflexão adorniana sobre o caráter irrevogável do elemento expressivo na atividade teórica, indaga-se como se dá a presença de menções literárias ficcionais em $O$ capital e quais papeis cumprem em sua argumentação; e em que medida essa forma de diálogo contribui para fomentar vínculos não hierárquicos entre o texto conceitual e o literário ficcional. A composição textual marxiana representa uma experimentação da lógica dialética; ela testemunha a lembrança do que Adorno chama de verdade e não verdade do exercício conceitual e de sua relação tensa e complementar com o expressivo. Essa posição vincula-se à luta contra a estreiteza e a unilateralidade do desenvolvimento humano decorrente da divisão social do trabalho no capitalismo que fratura capacidades e faculdades humanas. Carrega em si a utopia de um saber renovado que não se submete à força da identidade do princípio do valor.

PALAVRAS-CHAVE: Marx, Obra de arte literária, O capital.

ABSTRACT - From Adorno's reflection on the irrevocable character of the expressive element in theoretical activity, one wonders about the presence of fictional literary allusions in Marx's work, Capital, and what roles they perform in his argumentation; and also to what extent this form of dialogue contributes to foster non-hierarchical links between the conceptual text and the literary fiction. Marx's textual composition represents an experimentation of dialectical logic and bears witnesses to what Adorno calls the truth and non-truth of the conceptual exercise and of its tense and complementary relationship with expression. This position is associated with the struggle against the narrowness and onesidedness of human development resulting from the social division of labor in capitalism that fractures human capacities and faculties. It carries within itself the utopia of a renewed knowledge that does not submit to the force of the identity of the principle of value

KEYWORDS: Marx, Literary work of art, Capital.

Sandra Soares Della Fonte é professora do Programa de Pós-Graduação em Educação da Universidade Federal do Espírito Santo e Programa de Pós-Graduação em Ensino de Humanidades do Instituto Federal de Educação, Ciência e Tecnologia do Espírito Santo (campus Vitória). @ - sdellafonte@gmail.com / sdellafonte@uol.com.br / https://orcid.org/0000-0002-9514-7202

I Programa de Pós-Graduação em Ensino de Humanidades, Instituto Federal de Educação, Ciência e Tecnologia do Espírito Santo, Vitória, Espírito Santo, Brasil.

Recebido em 12.11.2018 e aceito em 10.12.2018. 
